\title{
Inhibiting Aspects of ICT Infrastructure in Kenyan Technical Institutions for Teaching Electrical Engineering
}

\author{
Mr. Solomon K. Kiplimo ${ }^{1 *}$, Prof. Kitainge M. Kisilu ${ }^{2}$, Dr. Wanami Simon ${ }^{3}$, Dr. Paul Wanyeki ${ }^{4}$ \\ ${ }^{1}$ Lecturer, Jeremiah Nyagah Technical Institute, P.o. Box 1264-60100, Embu, Kenya \\ ${ }^{2}$ Head of Department, Technology Education, University of Eldoret, P.o. Box 1125-30100, Eldoret, Kenya \\ ${ }^{3}$ Senior Lecturer, Technology Education, University of Eldoret, P.o. Box 1125-30100, Eldoret, Kenya \\ ${ }^{4}$ Lecturer, Technology Eduction, Dedan Kimathi University of science and Technology, P.o. box Private Bag, Nyeri, Kenya
}

\author{
DOI: $10.36348 /$ jaep.2020.v04i11.006 \\ | Received: 14.09.2020 | Accepted: 22.09.2020 | Published: 17.11.2020 \\ *Corresponding author: Solomon K. Kiplimo
}

\section{Abstract}

Information Communication Technologies have been incorporated in many sectors of the economy globally in the last two decades. In education, Governments around the world are investing large amounts of capital to achieve sustainable development through science, Technology and innovation. The use of ICT's as an addition to existing traditional methods of teaching is one of the evolutions that is transforming the education sector. This study investigated existing ICT infrastructure in the Kenyan Technical institutions so as to establish as to what extend they contribute to low integration of ICT's in teaching Electrical Engineering courses. The study achieved this by investigating the availability and use of computer systems and ICT equipment, influence of Supportive ICT infrastructure, Classroom internet connectivity and Conventional teaching by blackboards. The study adopted a descriptive survey study design. The study targeted Heads of departments and Trainers of Electrical Engineering in TVET institutions in Nairobi County. Data was collected using questionnaires; quantitative techniques were employed in data analysis. To a limited extend, the study established Mat Lab, presentation slides, CAD software; Smart boards, Desktop and Laptop computers among other ICT infrastructure are available for teaching Electrical Engineering in TVET institutions. Private institutions recorded higher level of ICT usage than public institutions. The study concluded that, computer systems and ICT support infrastructure as key determinants for successful ICT integration in Teaching Electrical Engineering courses. The findings of this study are essential to the government and stakeholders in TVET education and training towards the achievement of sustainable skills training that embrace technology and innovation.

Keywords: ICT, Infrastructure, TVET, CAD \& Teaching Infrastructure.

Copyright (C) 2020 The Author(s): This is an open-access article distributed under the terms of the Creative Commons Attribution 4.0 International License (CC BY-NC 4.0) which permits unrestricted use, distribution, and reproduction in any medium for non-commercial use provided the original author and source are credited.

\section{INTRODUCTION}

Integrating ICT in various sectors of the economy has been a global initiative by many governments in an effort to harness benefits that are realized by ICT's. In the education sector, efforts have been to ensure a widespread access to ICT infrastructure and data networks [1]. The Kenyan government has committed itself towards Upgrading National ICT Infrastructure so that a national ICT integration of the social, economic and political pillars of the vision 2030 may be realized.

Technical Vocational Education and Training (TVET) is central to the realization of the social pillar through reinforcement of Science, Technology and Innovation (STI) for Regional and Global Competitiveness. However, the quest to providing quality Technical Education in Kenya with a well ICT integrated teaching and learning is still a serious challenge [2]. This is an indication that much investment is still required in learning institutions to achieve integrated ICT teaching and learning. It is from the view of Kibata [3] that this study was undertaken. $\mathrm{He}$ identified five key factors (poor internet connectivity, lack of pronounced computer system in technical training institutions, inadequate ICT facilities as well as unequipped computer laboratories) which prevented TVET Teachers from implementing flexible and blended approaches in their teaching.

Studies on ICT integration in teaching have been conducted by many researchers in the past decade; these studies have given more emphasis on impact of new technology, its adoption in education rather than integration Veltman [4]. The Kenyan culture of 
continued use of blackboards and chalk in classroom pedagogy is in fact used as the only alternative for teaching due to insufficient infrastructure that support the use of new technology. Researchers $[5,6,7,3]$ have identified numerous reasons for low adoption of new technology in teaching and learning without giving clear insights as to what extent ICT infrastructure contributes. This study investigated how ICT infrastructural has contributed to low ICT use for teaching Electrical Engineering in TVET institutions. Factors identified in literature such as infrastructural facility, internet connection, ICT support equipment in teaching Electrical Engineering were investigated. The study expounds existing knowledge on ICT integration in TVET learning and provides basis for further research in integrated ICT teaching and learning.

\section{METHODOLOGY}

The researcher used survey research design in the study since it provides a method of obtaining large amounts of data from a large number of people in a relatively short time [8]. Survey questionnaire was used as the tool for data collection. The choice of a research methodology and data collection tools are influenced by research questions that seek to gain insight and construct explanations on the phenomenon under study [9]. This helped to describe the existing relationships between infrastructure and computer system in the public and private TVET institutions while trying to integrate ICT in teaching Electrical Engineering.

A target population of 100 electrical engineering trainers from ten technical training institutes in Nairobi County were randomly sampled as it reduces the chance of variation between a sample and the population it represents [10]. The questionnaires were pretested at Nairobi Technical Training Institute, Electrical Engineering department where a sample of ten electrical engineering lecturers were interviewed for the pretesting of the questionnaire. The choice of Nairobi Technical Training Institute as the center to pilot the instruments was based on proximity to the study location. The important corrections, clarifications, suggestions and omissions highlighted during the pre- testing exercise were then adopted and used to improve the study.

The study used Cronbach's alpha index to measure the reliability of the instrument. Cronbach's alpha is used to measure the internal consistency among a set of items. Reliability coefficient is considered good if it equals or exceeds $0.70[11,12]$. In the study, the items selected to measure reliability coefficient showed a reliability index of $(\alpha=0.7659)$.

\section{RESULTS AND DISCUSSIONS}

Ninety seven $(97 \%)$ response rates out of a sample size of 100 Electrical Engineering lecturers representing $51 \%$ respondents from the public technical institutions and $49 \%$ from the private technical institutions in Nairobi County participated in the survey. The demographics represented 17 women and 80 men whose ages were majorly 30-39 years representing $51.5 \%$ of the total respondents while the least were respondents above 50 years of age representing $3.1 \%$ of the study population.

According to the study, most trainers had only taught for less than 10 years and a good percentage of them $69.1 \%$ were holders of a bachelor's degree.

The study sort to establish usage of desktop computers, laptops and mobile phones in teaching Electrical Engineering in Technical Training Institutions, Figure 1 outlines the results of these findings. The respondents were asked whether they use computers upon requests, in all lessons, in some lessons or not at all. The survey indicates that computers are only used in teaching some lessons with Laptop computers being highly used $(60.8 \%)$ compared to desktop $(57.7 \%)$ and mobile phones $(36.1 \%)$. The results also indicates some trainers did not use computers at all in their teaching with mobile phones rarely used (48.8\%) followed by desktop computers $(26.8 \%)$ then laptop computers $(9.2 \%)$. These results indicate ICT integration in teaching of Electrical Engineering is still low.

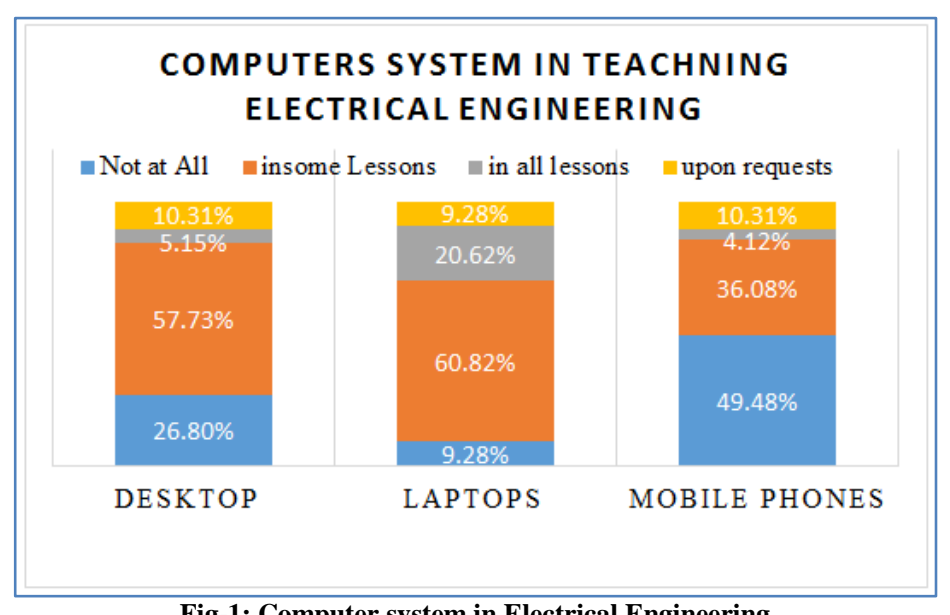

Fig-1: Computer system in Electrical Engineering 
The study sort to establish the availability of other ICT supporting infrastructure such as smart boards, interactive whiteboards, LCD Projectors, teleconferencing facilities and Audio/Video equipment in the teaching of Electrical Engineering as shown in figure 2. It was found that video conferencing (96\%), smart boards (92\%), CD/DVDs (47\%) interactive boards $(45 \%)$, and LCD projectors $(37 \%)$ were hardly used by trainers in teaching of Electrical Engineering. LCD projectors (45\%), CD/DVDs (38\%) \& whiteboards $(26 \%)$ were used in some lessons by trainers in teaching electrical engineering.

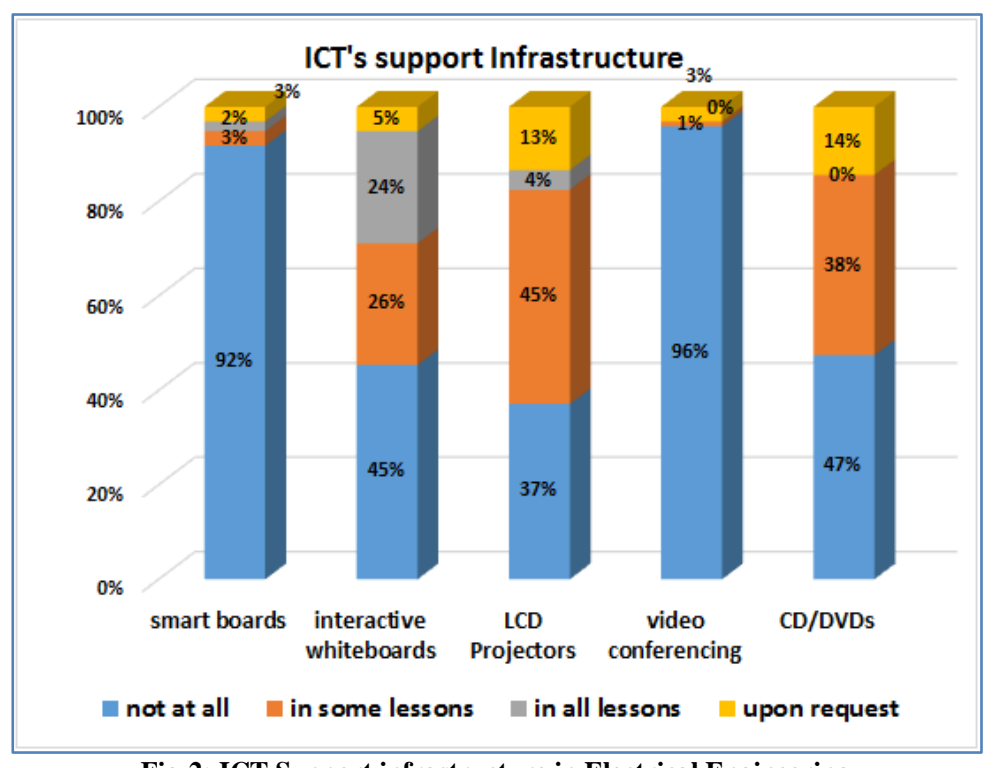

Fig-2: ICT Support infrastructure in Electrical Engineering

From the analysis, figure 2, the study established Mat Lab, presentation slides, CAD software; Smart boards, Desktop and Laptop computers among other ICT infrastructure are inadequate in TVET institutions. Finally, the results established computer systems and ICT support structures are key determinants for successful ICT integration in teaching Electrical Engineering courses.

This study was designed to determine the extent to which infrastructure contributed to low ICT integration in teaching Electrical Engineering courses in Technical Training Institutions in Kenya. It was realized that many factors contributed to low integration of ICT use in teaching electrical engineering with infrastructure playing a major role. The first Specific objective was to establish the available ICT's in Electrical Engineering departments in Technical Institutions in Kenya. The study established MatLab software, CAD software, lecturer slides, CD's and DVD', Laptop computers, LCD projectors, Mobile phones, smart boards, interactive white boards, workbench software and video conferencing in few institution where ICT's available in TVET institutions without which no integration of ICTs in teaching electrical engineering was realized.

The second specific objective was to find out relevant ICT support equipment used for teaching electrical engineering in Technical institutes in Kenya. From the literature review the ICT's were classified into Computer systems infrastructure and ICT supporting infrastructure. The computer systems identified in this study comprised of desktop computer, laptop computers and mobile phones. The laptop computers were found to be the most used type by many lecturers followed by desktop computers while mobile phones were hardly used in teaching electrical engineering. The computer support infrastructure identified in this study included presentation slides, CAD software, Mat Lab software and Electronic workbench.

Specific objective number three was to establish which factors hinders the most the effective use of ICT's in teaching Electrical Engineering in Technical Training Institutes in Kenya. The study used factor analysis to reduce factors identified in literature into three factors. The factors identified in literature include computer system, ICT supportive equipment and internet connectivity. Factor analysis grouped these variables into three key factors that hinder integration of ICT in teaching and learning of Electrical engineering courses. However the computer system emerged the most influential of the three, followed by ICT support equipment and internet connectivity respectively.

The research objectives guided the research and data analysis. The study aimed at analyzing infrastructural factors that inhibit ICT integration in teaching electrical engineering in Kenya. There has been incredible uptake of ICT in many sectors in the recent past. Education practitioner's view ICT as a tool that will transform the education sector ranging from content availability, teaching methods to transmission 
of content. Regardless of the advancements in ICT's, there remain many infrastructural obstacles that must be addressed in order to enhance efficient integration of ICT in teaching [13].

\section{CONCLUSION AND RECOMMENDATIONS}

The study achieved what it set to accomplish, identify infrastructural factors that contribute to low integration of ICT in teaching Electrical Engineering courses in TVET institutions. The findings obtained in this study and information obtained from literature, is evident that ICT integration in the teaching of Electrical and Electronic engineering has not been widely adopted because of insufficient ICT facilities in our institutions causing serious infrastructural gaps that needs urgent resolution.

There are a number of challenges that are hindering the adoption of ICT's in teaching in TVET institutions. This study presents the following recommendation to enhance integrated ICT teaching and learning of Electrical Engineering courses in Kenya.

The government and other stakeholders in TVET should provide adequate ICT infrastructure from computer systems, supportive equipment and their networks.

Trainers' Professional development courses should put emphasis on trainers ICT literacy, competence and modern pedagogy.

ICT incorporated Training curricula tailor made to specific courses (such as engineering simulation) should be designed to enable TVET trainers to make good use of the existing infrastructure in training of the learners.

\section{REFERENCES}

1. Taylor, R., \& Zhang, B. (2007, September). Measuring the impact of ICT: theories of information and development.

\author{
In Telecommunications Policy Research \\ Conference (pp. 26-28).
}

2. Gakuu, D. C., \& Kidombo, D. H. (2008). National Research Report- Kenya. Nairobi: University of Nairobi.

3. Kibata, F. M. (2012). Factors that Prevent TVET Teachers from Implementing Flexible and Blended Approaches in Their Teaching. Kajiado County, Kenya: Masai Technical Training Institute.

4. Veltman, K. H. (2003). Challenges for Information and Communication Technologies (ICT) Applications in Cultural Heritage in the Next Decade(s). Instituto Andaluz del Patrimonio Historico, 1-25.

5. Farrell. (2007). ICT in Education in Kenya. Nairobi: world Bank.

6. Makori, A., \& Onderi, H. (2013). Evaluation of Secondary School Principals' Views on the Use of Untrained Teachers in Lesson Delivery in a Free Secondary Education System Era in Kenya. Journal of Education and Practice, 119-134.

7. Wanyeki, P. (2011). Adoption of new Technology by Jua Kali Automobile Mechanics in Eldoret Municipality. Research Thesis, 1-113.

8. McNeill, P., \& Chapman, S. (1985). Research Methods Third Edition. USA and Canada: Routledge.

9. Ngure, S. W. (2013). Stakeholders' Perceptions of Technical, Vocational Education and Training: The Case of Kenyan Micro and Small Enterprises in the Motor Vehicle Service and Repair Industry. Edith Cowan University: Faculty of Business and Law.

10. Mugenda, O., \& Mugenda, A. (1999). Research Methods:Quantitatives and Qualitative Approaches. Nairobi: Acts Press.

11. Litwin, S. (1995). Principles and practices of education. Singapore: Longman.

12. Nunnally, J. C. (1978). Psychometric Theory (2nded.). New York: Mcgraw-Hill.

13. Gaible, E. (2008). Survey of ICT and Education in the Caribbean: A summary report, Based on 16 Country Surveys. Washington, DC: infoDev / World Bank. Available at hppt://www.infodev.org/en/Publication.441.html. 